\title{
Influence of different polishing and aging periods on the surface roughness of
}

\section{composite resins}

Influência de diferentes períodos de polimento e envelhecimento na rugosidade superficial de resinas compostas

Influencia de diferentes periodos de pulido y envejecimiento en la rugosidad superficial de las resinas compuestas

\begin{abstract}
The aim of this study was to evaluate the influence of the polishing period on surface roughness (Ra) before and after thermal aging in four composite resins - CR (Durafill VS, Vittra APS, Filtek Z350XT and Spectra Smart). This in vitro study evaluated: (1) CR in 4 levels; (2) polishing period (PP) in three levels (immediate, 7 and 14 days) and (3) artificial aging in two levels: without aging and after 10,000 cycles. For this, $240 \mathrm{CR}$ specimens were allocated into 12 groups $(\mathrm{n}=20)$ according to PP with SofLex Pop On disks. For Ra, 3 measurements on the top surface of each specimen were performed with a diamond tip and constant load of $4 \mathrm{mN}$ and $0.25 \mathrm{~mm} / \mathrm{s}$. Next, the specimens were aged in thermocycling, with temperatures of $5^{\circ}$ and $55^{\circ} \mathrm{C}$, during 30 seconds in each temperature, and repeated testing afterwards. The data were submitted to statistical tests with 5\% significance. The alteration in Ra was observed only in the late polishing in the period of 7 days, where the Durafill VS CR showed higher Ra in comparison to the other CRs. After thermocycling, the groups showed significant difference only with late polishing in the 21-day period; the nanoparticulated RCs (Z350XT $<$ Vittra APS) recorded the highest Ra values, followed by the microhybrid (DurafillVS) and nanohybrid (Spectra Smart) RCs, respectively. Thus, late polishing in the 7-day and immediate period provided higher Ra values, especially for the nanohybrid and microhybrid composite resins.

Keywords: Dental polishing; Composite resins; Aging; Dental restoration failure; Permanent dental restoration; Operative dentistry.
\end{abstract}

\section{Resumo}

O objetivo deste estudo foi avaliar a influência do período de polimento na rugosidade superficial (Ra) antes e após o envelhecimento térmico em quatro resinas compostas - RC (Durafill VS, Vittra APS, Filtek Z350XT e Spectra Smart). Trata-se de um estudo in-vitro, avaliando: (1) RC em 4 níveis; (2) período de polimento (PP) em três níveis (imediato, 7 e 14 dias) e (3) envelhecimento artificial em dois níveis: sem envelhecimento e com 10.000 ciclos. Para tanto, 240 corpos-de-prova (CD) de RC foram alocados em 12 grupos $(n=20)$ de acordo com o PP com discos SofLex Pop On. 
Para a Ra, 3 medições na superfície superior de cada CD foram realizadas com ponta de diamante e carga constante de $4 \mathrm{mN}$ e $0,25 \mathrm{~mm} / \mathrm{s}$. Em sequência, os $\mathrm{CD}$ foram envelhecidos em termociclagem, com temperaturas de $5^{\circ}$ e $55^{\circ} \mathrm{C}$, tempo de permanência de 30 segundos e repetição de testes posteriormente. Os dados foram submetidos à testes estatísticos com significância de 5\%. A alteração da Ra foi observada apenas no polimento tardio no período de 7 dias, onde a RC Durafill VS apresentou maior Ra em comparação com as demais RCs. Após a termociclagem, os grupos apresentaram diferença significativa apenas com polimento tardio no período de 21 dias; as RCs nanoparticuladas (Z350XT<Vittra APS) registraram os maiores valores de Ra, seguidas das RCs micro-híbridas (DurafillVS) e nanohíbridas (Spectra Smart), respectivamente. Assim, o polimento tardio no período de 7 dias e imediato proporcionou maiores valores de Ra, principalmente para as resinas compostas nanohíbridas e microhíbridas.

Palavras-chave: Polimento dentário; Resinas compostas; Envelhecimento; Falha de restauração dentária; Restauração dentária permanente, Dentística operatória.

\section{Resumen}

El objetivo de este estudio fue evaluar la influencia del período de pulido en la rugosidad superficial (Ra) antes y después del envejecimiento térmico en cuatro resinas compuestas - RC (Durafill VS, Vittra APS, Filtek Z350XT y Spectra Smart). Este es un estudio in vitro, que evalúa: (1) RC en 4 niveles; (2) período de pulido (PP) en tres niveles (inmediato, 7 y 14 días) y (3) envejecimiento artificial en dos niveles: sin envejecimiento y con 10.000 ciclos. Para ello, se asignaron 240 muestras de RC (DC) a 12 grupos $(n=20)$ según el PP con discos SofLex Pop On. Para Ra, se realizaron 3 mediciones en la superficie superior de cada $C D$ con punta de diamante y carga constante de $4 \mathrm{mN}$ y 0,25 $\mathrm{mm} / \mathrm{s}$. En secuencia, las CD fueron envejecidas en termociclado, con temperaturas de $5^{\circ}$ y $55^{\circ} \mathrm{C}$, tiempo de residencia de 30 segundos y posterior repetición de pruebas. Los datos fueron sometidos a pruebas estadísticas con una significancia del 5\%. El cambio en el Ra se observó solo en el pulido tardío en el período de 7 días, donde el RC Durafill VS presentó mayor Ra en comparación con los otros RC. Después del termociclado, los grupos mostraron una diferencia significativa solo con pulido tardío en el período de 21 días; Los RC nanoparticulados (Z350XT $<$ Vittra APS) registraron los valores de Ra más altos, seguidos de los RC microhíbridos (DurafillVS) y nanohíbridos (Spectra Smart), respectivamente. Así, el pulido tardío en el período de 7 días e inmediato proporcionó valores de Ra más altos, principalmente para las resinas compuestas nanohíbridas y microhíbridas.

Palabras clave: Pulido dental; Resinas compuestas; Envejecimiento; Falla de restauración dental; Restauración dental permanente; Odontología operatoria.

\section{Introduction}

Because the ability to mimic the characteristics of dental tissues, composite resins have made it possible to make truly imperceptible restorations (Alonso, Darriba, \& Caserío, 2017; Pallesen \& van Dijken, 2015). Thus, the unique combination of aesthetics, accessibility and greater preservation of healthy dental structure, in recent years, has reported good clinical performance when associated with the applicability of composite resin (Duarte \& Saad, 2008; Opdam et al., 2014). In addition, they have become one of the most used restorative materials for aesthetic-functional oral-rehabilitation (Alonso et al., 2017).

The aesthetic aspect of CR is achieved based on the shape, the final color, the surface smoothness and the gloss of the restorations obtained by the procedures of finishing, polishing, keepingthe polished surface for a long period in the oral environment (Freitas et al., 2020; Schmitt et al., 2011; Tuncer, Karaman, \& Firat, 2013). A perfectly polished surface prevents the retention of biofilm, the formation of early superficial marginal discoloration, gingival irritation, and reduces the risk of developing secondary caries due to the absence of micro-roughness (Babina et al., 2020; da Silva, da Rocha, Travassos, Fernandes, \& Rodrigues, 2010; Schmitt et al., 2011; Soliman et al., 2020; Tuncer et al., 2013).

However, the successful the ability of polish of composite resins can be challenging. Some reports in the literature correlate early restoration failures and marginal defects from the finishing and polishing process (Hassan, Nabih, Mossa, \& Baroudi, 2015). This occurs, since these are affected by the technique and time of polishing, in addition to being sensitive to the characteristics and composition of the material (Babina et al., 2020; Hassan et al., 2015).

In the literature, the methods of finishing and polishing are well-documented; being an essential step to minimize problems related to premature failures and guaranteed the success of a restoration (Duarte \& Saad, 2008; Gönülol \& Yilmaz, 2012; Turssi, Saad, Duarte, \& Rodrigues, 2000). However, there is a lack of information about when is the best time to polish the CR. This topic is still remains a controversial topic (Opdam et al., 2014; Schmitt et al., 2011). Polishing at the wrong time 
can affect physical properties, causing irreversible damage and failure in restorations (Babina et al., 2020; Hassan et al., 2015; Yap, Yap, Teo, \& Ng, 2004).

Thus, in view of the importance of achieving an extremely polished surface, the literature suggests that polishing can be carried out either immediately or late ( 7 or 21 days after completion of the restoration). In this sense, it is interesting to investigate the best polishing moment for composite resins, and how this affects the long-term maintenance of the polished surface, simulated by means of thermal cycling. Thus, the objective of this research was to evaluate the influence of the immediate and late polishing ( 7 and 21 days) on the surface roughness before and after aging of 10.000 thermal cycles of four composite resins. In this way, the following hypotheses were tested: the different polishes (immediate and late 7 and 21 days) will not influence the surface roughness of the composite resins; and the surface roughness will not be influenced by thermal aging.

\section{Methodology}

\subsection{Experimental design}

This is an in-vitro study which analyzed the following study factors: (1) restorative material, on four levels (Durafill VS, Vittra APS, Filtek Z 350 XT and Spectra Smart), (2) polishing period, on three levels (immediate polishing, after 7 and 21 days) and (3) artificial aging in two levels (without aging and with 10.000 aging cycles. The sample consisted of 240 specimens in the form of a resin disk. The response variable was surface roughness (Table1) (da Silva, et al., 2010; Dhananjaya, et. al., 2019; Bansal, et. al., 2019).

Table 1. Products (Material, Manufacturer and Composition) used in this study.

\begin{tabular}{|c|c|c|c|c|}
\hline Group & Material & Manufacturer & Composition & Batch number \\
\hline $\begin{array}{l}\text { G I } \\
\text { G V } \\
\text { G IX }\end{array}$ & $\begin{array}{c}\text { Durafill VS } \\
\text { (Microparticulate ) }\end{array}$ & $\begin{array}{l}\text { Kulzer } \\
\text { (Sao Paulo, SP, } \\
\text { BR) }\end{array}$ & $\begin{array}{l}\text { Organic matrix: } \text { Bis-GMA; } \\
\text { Inorganic particle loading: Highly dispersed silicon } \\
\text { dioxide, sizes ranging from } 0.02 \mu \mathrm{m} \text { to } 0.07 \mu \mathrm{m} \text { and } \\
\text { fluorinated aluminum barium glass with sizes ranging } \\
\text { from } 0.02 \mu \mathrm{m} \text { to } 2 \mu \mathrm{m} \text {, with an average particle size of } \\
\qquad 0.7 \mu \mathrm{m} \text {; }\end{array}$ & K010228 \\
\hline $\begin{array}{l}\text { G II } \\
\text { G VI } \\
\text { G X }\end{array}$ & $\begin{array}{c}\text { Vittra APS } \\
\text { (Nanoparticulate) }\end{array}$ & $\begin{array}{c}\text { FGM } \\
\text { (Joinville, SC, BR) }\end{array}$ & $\begin{array}{c}\text { Organic matrix: Mixture of methacrylate monomers; } \\
\text { Inorganic particle loading: charge particles of } \\
\text { zirconia and silica; }\end{array}$ & 030417 \\
\hline $\begin{array}{l}\text { G III } \\
\text { G VII } \\
\text { G XI }\end{array}$ & $\begin{array}{c}\text { Filtek Z350XT } \\
\text { (Nanoparticulate) }\end{array}$ & $\begin{array}{c}\text { 3M ESPE } \\
\text { (Sumare, SP, BR) }\end{array}$ & $\begin{array}{l}\text { Organic matrix: Bis-GMA, UDMA, TEGDMA and } \\
\qquad \text { Bis-EMA; } \\
\text { Inorganic particle loading: combination of non- } \\
\text { agglomerated / non-aggregated 20nm silica, 4-11nm } \\
\text { non-agglomerated / non-aggregated zirconia and } \\
\text { agglomerates, clusters, aggregated zirconia / silica } \\
\text { particles (combination of particles of zirconia / silica) } \\
\text { silica with 20nm and Zirconia } 3 \text { with 4-11 nm); }\end{array}$ & 1812800724 \\
\hline $\begin{array}{l}\text { G IV } \\
\text { G VIII } \\
\text { G XII }\end{array}$ & $\begin{array}{l}\text { Spectra Smart } \\
\text { (Nanohybrid) }\end{array}$ & $\begin{array}{c}\text { Dentsply } \\
\text { (Pirassununga, SP, } \\
\text { BR) }\end{array}$ & $\begin{array}{c}\text { Organic matrix: Dimethacrylate monomers; } \\
\text { Inorganic particle loading: Glass Powder, Silica, } \\
\text { Hydrophobic Colloid; }\end{array}$ & $325958 \mathrm{~J}$ \\
\hline
\end{tabular}




\subsection{Preparation of specimens}

The sample consisted of 240 specimens, 60 from each CR, which was divided into 3 subgroups according to the three basic principles of experimentation (repetition, randomization and blocking). The distribution of specimens according to the study groups is shown in Figure 1.

For this, a split Teflon matrix was made with holes $6 \mathrm{~mm}$ in diameter and $4 \mathrm{~mm}$ thick. A polyester strip was placed on a glass plate, followed by this split Teflon matrix, then the composite resin was inserted by the incremental technique in $2 \mathrm{~mm}$ increments until the desired thickness was completed. Light curing was performed at the end of the insertion of each increment following the recommendation of each manufacturer (Table 1).

Prior to final light cure, a second strip of polyester and a glass plate were placed on the split Teflon matrix, in order to ensure that the resin is better accommodated and the surfaces of the specimens are flat. Then, only the glass plate was removed, keeping the polyester strip in position. The polywave LED unit was used (VALO® Cordless, Ultradent, UT, USA) for the time recommended for each resin with $1000 \mathrm{~mW} / \mathrm{cm}^{2}$ power.

In order to obtain a flat and standardized surface, the specimens were fixed to a cylindrical acrylic resin base (JET, Classic Dental Articles Ltda, Campo Limpo Paulista, SP, Brazil) with the help of sticky wax (ASFER Indústria Química Ltda, SP, Brazil) and initially grinded with 800 and 1200 grit aluminum oxide sandpaper for 30 seconds at $100 \mathrm{rpm}$ in each grit, following the decreasing order of abrasiveness. At the end of the abrasiveness protocol, the discs were washed in an ultrasonic tub and distilled water for 5 minutes.

Figure 1. Flowchart showing the distribution of composite resins at different times for the analysis of roughness.

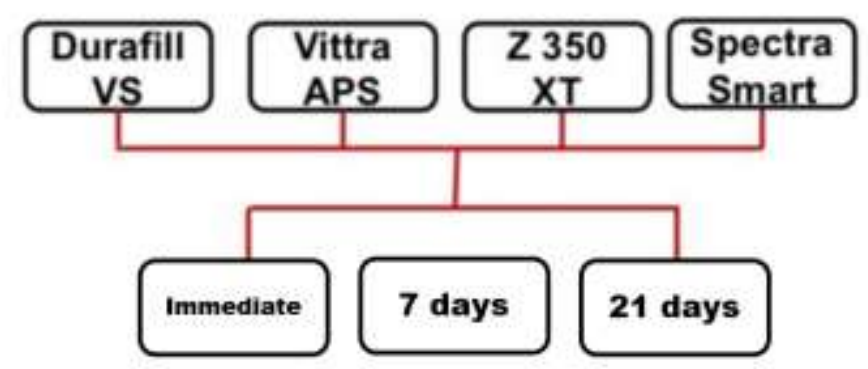

\section{Polishing with Sof-Lex Pop on discs}

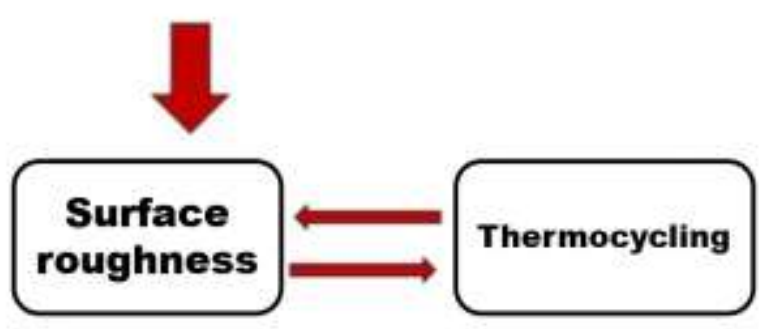

Source: Authors (2021).

\subsection{Finishing, polishing and storage of specimens}

To simulate the same aspects of CR restorations found in clinical practice, the surface of all specimens was immediately finished with an extra-fine-grained diamond tip (KG Sorensen, SP, Brazil) until it reached a thickness of $3.5 \mathrm{~mm}$, these measurements were measured with a digital caliper (Mitutoyo Corporation, Tokyo, Japan), with an accuracy of $0.01 \mathrm{~mm}$. 
The specimens of groups G I, GII, GIII and G IV had their surfaces immediately polished after the specimens were made. The specimens of groups G V, GVI, GVII and G VIII were stored in a humidifying chamber with a temperature of $37^{\circ} \mathrm{C}$, using gauze soaked with distilled water for 7 days. After this storage period, the discs received the chosen to polish protocol. The specimens of groups G IX, GX, GXI and G XII remained stored in the same humidifying chamber mentioned above for 21 days, and only after having their surfaces polished with the polishing system of choice for the study.

The polishing systems adopted in this study were Sof-Lex Pop On (3M ESPE, SP, Brazil), which was executed in decreasing order of granulation. For this, the discs were coupled in a contra-angle, with circular and continuous movements, with controlled load through the calibration of the operator, and they were positioned on the surface of the specimens until the desired thickness was obtained. Larger (red) and medium (dark orange) discs were used until the thickness of 2.5 and $2.4 \mathrm{~mm}$ was obtained, respectively. Subsequently, fine-grained (light orange) and extra-fine (yellow) discs were used for 20 seconds each, which provide negligible wear but reproduce the desired brightness of the procedure at the end (Kocaagaoglu et al., 2017). Between each disk, the sample was washed with a jet of water and air.

After finish the polishing and prior to mechanical testing, the discs were cleaned in an ultrasonic tub and distilled water for 5 minutes.

\subsection{Thermal storage and cycling}

After, the specimens were stored for a period of 7 (groups V to VIII) and 14 days (groups IX to XII) in a humidifying chamber with a temperature of $37^{\circ} \mathrm{C}$, using gauze soaked with distilled water. Then, the surface roughness analysis was performed before aging.

After the initial analyzes, the same specimens received 10,000 thermal cycles performed in a thermal cycling machine (Model 521-4D - Nova Ética Ind., Com e Serv Ltda, SP, Brazil), configured for bathing in water at temperatures of $5{ }^{\circ}$ and 55 ${ }^{\circ} \mathrm{C}$, with a residence time of 30 seconds. Subsequently, the aged specimens were subjected to the same analysis.

\subsection{Surface roughness analysis}

After cleaning the specimens in an ultrasonic cleaner and distilled water, the roughness parameter Ra was measured using a rugosimeter (Surftest SJ 201; Mitutoyo Corp). To measure the roughness in micrometers, a diamond tip $(\mathrm{r}=5 \mu \mathrm{m})$ was moved over the specimens' surface with a constant load of $4 \mathrm{mN}$ with a speed of $0.25 \mathrm{~mm} / \mathrm{s}$. Three measurements were made on each specimen in different places. Based on these measurements, the arithmetic mean of the roughness of each specimen was calculated.

\subsection{Statistical analysis}

The averages of the roughness values were calculated and the results were submitted to the normality curve adherence test (Shapiro - Wilk Test). Since the variables had a normal distribution, two-way ANOVA was used for repeated measures and Tukey's post-test $(\mathrm{p}<0.05)$.

\section{Results}

\subsection{Roughness before thermal aging}

The results of the roughness obtained in the different polishing periods for each type of composite resin before thermal aging are shown in Table 2.

Lookink for the roughness between the composite resins before thermal aging, it was observed that there was a significant difference only in the late polishing of the 7-day period, where the Durafill VS (GV) resin presented higher surface 
roughness than Vittra APS (G VI), Z 350 XT (G VII) and Spectra Smart (G VIII) (p <0.05). In the immediate and late polishing periods of 21 days, there were no differences between the resins.

Between the polishing periods for each resin, there was a significant difference for Durafill VS and Spectra Smart resins, where the highest values of surface roughness were recorded in the 7 days (GV) and immediate (G II) polishing periods, respectively $(\mathrm{p}<0.05)$. Similarities for resins Z 350 XT and Vittra APS were recorded for all polishing periods $(\mathrm{p}<0.05)$.

Table 2. Mean and standard deviation of the roughness before thermal aging, according to the types of composite resins and polishing periods.

\begin{tabular}{cc|l|l|l}
\cline { 2 - 5 } & \multicolumn{5}{c}{ Resin } \\
\hline $\begin{array}{l}\text { Polishing } \\
\text { period }\end{array}$ & Durafill VS & Vittra APS & Z 350 XT & Spectra Smart \\
\hline Immediate & G I & G II & G III & G IV \\
& $0,24 \pm 0,15 \mathrm{Ba}$ & $0,22 \pm 0,06 \mathrm{Aa}$ & $0,22 \pm 0,10 \mathrm{Aa}$ & $0,37 \pm 0,23 \mathrm{Aa}$ \\
\hline \multirow{2}{*}{7 days } & $0,68 \pm 0,45 \mathrm{Aa}$ & $0,21 \pm 0,14 \mathrm{Ab}$ & $0,24 \pm 0,16 \mathrm{Ab}$ & $0,10 \pm 0,05 \mathrm{Bb}$ \\
\hline \multirow{2}{*}{21 days } & $0,15 \pm 0,07 \mathrm{Ba}$ & $0,14 \pm 0,09 \mathrm{Aa}$ & $0,22 \pm 0,18 \mathrm{Aa}$ & $0,08 \pm 0,02 \mathrm{Ba}$
\end{tabular}

Means followed by different letters, uppercase letters (within column) compare the polishing periods for the same composite resin and lowercase letters (within row) compare compare the different composite resins in a polishing period, are significantly different ( $\mathrm{p}<0.05$ ). Source: Authors.

\subsection{Roughness after thermal aging}

The results of roughness after thermal aging are shown in Table 3. In the comparison between the composite resins, there was a similarity in the periods of immediate and late polishing of 7 days, with a difference being recorded only in the late polishing of 21 days ( $\mathrm{p}<0.05$ ); In this period, the nanoparticulate composite resins Z 350 XT (GXI) and Vittra APS (GX) registered the highest values of surface roughness, followed by Durafill VS (G IX) and Spectra Smart (G XII), respectively (p $<0.05)$.

When comparing the polishing periods for each composite resin, there was a significant difference only for microhybrid and nano-hybrid resins ( $\mathrm{p}<0.05$ ). Durafill VS recorded higher and lower values of roughness with late polishing in the period of 7 (G V) and 21 days (G IX), respectively. Spectra Smart showed a decrease in roughness between the polishing periods (immediate $>7$ days $>21$ days), with a difference only between the immediate and late polishing of 7 days with that of 21 days ( $\mathrm{p}$ <.05). For the nanoparticulate resins (Z 350 XT and Vittra APS) there was a similarity between the polishing periods. 
Table 3. Mean and standard deviation of the roughness after thermal aging, according to the types of composite resins and polishing periods.

\begin{tabular}{|c|c|c|c|c|}
\hline & \multicolumn{4}{|c|}{ Resin } \\
\hline $\begin{array}{c}\text { Polishing } \\
\text { period }\end{array}$ & Durafill VS & Vittra APS & Z 350 XT & Spectra Smart \\
\hline Immediate & $\begin{array}{c}\text { G I } \\
0,26 \pm 0,14 \mathrm{AB} \text { a }\end{array}$ & $\begin{array}{c}\text { G II } \\
0,25 \pm 0,18 \mathrm{~A} \mathrm{a}\end{array}$ & $\begin{array}{c}\text { G III } \\
0,19 \pm 0,15 \mathrm{~A} \mathrm{a}\end{array}$ & $\begin{array}{c}\text { G IV } \\
0,29 \pm 0,21 \mathrm{~A} \mathrm{a}\end{array}$ \\
\hline 7 days & $\begin{array}{c}\text { G V } \\
0,61 \pm 0,45 \mathrm{~A} \text { a }\end{array}$ & $\begin{array}{c}\text { G VI } \\
0,25 \pm 0,32 \mathrm{~A} \mathrm{a}\end{array}$ & $\begin{array}{c}\text { G VII } \\
0,26 \pm 0,24 \mathrm{~A} \mathrm{a}\end{array}$ & $\begin{array}{c}\text { G VIII } \\
0,20 \pm 0,25 \mathrm{~A} \mathrm{a}\end{array}$ \\
\hline 21 days & $\begin{array}{c}\mathbf{G ~ I X} \\
0,11 \pm 0,03 \mathrm{~B} \mathrm{~b}\end{array}$ & $\begin{array}{c}\mathbf{G ~ X} \\
0,16 \pm 0,11 \mathrm{~A} \mathrm{ab}\end{array}$ & $\begin{array}{c}\text { G XI } \\
0,25 \pm 0,26 \mathrm{~A} \mathrm{a}\end{array}$ & $\begin{array}{c}\text { G XII } \\
0,08 \pm 0,02 \mathrm{~B} \mathrm{c}\end{array}$ \\
\hline
\end{tabular}

Means followed by different letters, uppercase letters (within column) compare the polishing periods for the same composite resin and lowercase letters (within row) compare compare the different composite resins in a polishing period, are significantly different ( $\mathrm{p}<0.05$ ). Source: Authors.

\section{Discussion}

The surface roughness obtained by polishing at different times directly influences the success and longevity of composite resin restorations (Kaminedi, Penumatsa, Priya, \& Baroudi, 2014; Lu, Roeder, Lei, \& Powers, 2005). When evaluating the roughness at different polishing times, in the present study, the best values of surface roughness were obtained with the late polishing of 21 days before and after thermal aging, except for the resin Z 350 XT, which did not obtain any difference between the analyzed periods. In the immediate polishing, the Spectra Smart and Vittra APS resins showed high roughness, however, the highest roughness value was obtained with Durafill VS in the 7 days late polishing. Seen this, the first and second null hypotheses were rejected.

However, studies such as Venturini et al., and Yazici et al, stated that the success of dental polishing is closely related to the type of $\mathrm{CR}$, time and adopted technique chosen by the operator, indicating that immediate polishing does not produce any harmful effects in comparison with delayed polishing.

In addition, in the present study, the influence of immediate and late polishing on the surface roughness in different composite resins was verified, as well as the maintenance of this polishing after 1 year, simulated by means of thermocycling. Corroborating these findings, the study by da Silva, et al., observed good maintenance of polishing and smoothness when compared to analyze without the thermal aging process.

Asmussen and Jorgensen, stated that the immediate polishing causes a plastic deformation in the composite resin, increasing the surface roughness (Asmussen \& Jorgensen, 1972), since, after light curing, the composite reaches only $75 \%$ of its cure (Asmussen \& Jorgensen, 1972), corroborating with the data found in this study, which presented the best results of roughness when the 21 days late polishing was performed.

While some manufacturers affirm that the polishing process should be done at the end of the restoration, some authors recommend that the late polishing is the ideal period, being performed preferably 24 hours and up to 7 days after the restoration are made (de Morais, Garcia Lda, Cruvinel, \& Panzeri Pires-de-Souza Fde, 2015). This time interval would allow the absorption of water by the composite resin, triggering the hygroscopic expansion that would help to compensate for the polymerization contraction and in the best conversion of the monomers into polymeric chains (de Morais et al., 2015).

Chung et al, showed that restorations with a surface roughness of less than $1 \mu \mathrm{m}$ appear perfectly smooth (Chung, 1994). The presence of micro-roughness greater than $0.2 \mu \mathrm{m}$ on the surfaces of the restorations promotes the accumulation of 
plaque, making them predispose to deteriorate in a short period and cause gingival inflammation (Kaminedi et al., 2014). In this way, in this study, all samples of composite resins showed surface roughness less than $1 \mu \mathrm{m}$.

In addition, it was still possible to observe that despite the use of the same finishing and polishing technique, different composite resins have different patterns of surface roughness, especially for microparticulate resin (Durafill VS). This is because polishing and its maintenance are influenced by the composition of the organic matrix and dispersion of the particles of fillers (Kaminedi et al., 2014).

During the polishing procedure, the organic matrix wears away more easily than the filler particles, which remain exposed on the surface and are more likely to separate from the material. The loss of these particles results in defects in the surface of the material, making it more irregular, justifying the result found.

The combination of particles of nanometric charges in small agglomerates provides better polishing characteristics for nanoparticulate resins when compared to other types of resins. This can be justified because, during polishing, the primary particles, and not the agglomerates themselves, come loose, thus the surface roughness appears smoothly and is maintained over time (Kaminedi et al., 2014). Unlike these nanometric composites, the particle size of the micro-hybrid resin is larger, leaving the surface rough due to the removal of the charge particles after the resin matrix is worn out during polishing.

However, even though the results obtained in this study clarify important points about the surface roughness of composite resins when using different polishing periods, some limitations need to be taken into account. In this study, we considered roughness solely, however, further studies are needed, encompassing other mechanical properties.

\section{Conclusion}

It is concluded that late polishing in the period of 7 days and immediate provided higher values of surface roughness, especially for the nanoparticulate and microparticulate composite resins. In nanoparticles, however, the polishing period was not a relevant factor in relation to surface roughness.

\section{References}

Alonso, V., Darriba, I. L., \& Caserío, M. (2017). Retrospective evaluation of posterior composite iseppiresin sandwich restorations with Herculite XRV: 18-year findings. Quintessence Int, 48(2), 93-101. 10.3290/j.qi.a37386

Asmussen, E., \& Jorgensen, K. D. (1972). A microscopic investigation of the adaptation of some plastic filling materials to dental cavity walls. Acta Odontol Scand, 30(1), 3-21. 10.3109/00016357209004588

Babina, K., Polyakova, M., Sokhova, I., Doroshina, V., Arakelyan, M., \& Novozhilova, N. (2020). The Effect of Finishing and Polishing Sequences on The Surface Roughness of Three Different Nanocomposites and Composite/Enamel and Composite/Cementum Interfaces. Nanomaterials (Basel), 10(7). $10.3390 /$ nano 10071339

Bansal, K., Gupta, S., Nikhil, V., Jaiswal, S., Jain, A., \& Aggarwal, N. (2019) Effect of different finishing and polishing systems on the surface roughness of the composite resin and enamel: a study of scanning electron microscopy and in vitro profilometry. Int J Appl Basic Med Res. 9(3):154-158

Chung, K. H. (1994). Effects of finishing and polishing procedures on the surface texture of resin composites. Dent Mater, 10(5), 325-330. 10.1016/01095641(94)90041-8

da Silva, J. M., da Rocha, D. M., Travassos, A. C., Fernandes, V. V., Jr., \& Rodrigues, J. R. (2010). Effect of different finishing times on surface roughness and maintenance of polish in nanoparticle and microhybrid composite resins. Eur J Esthet Dent, 5(3), 288-298.

de Morais, R. C., Garcia Lda, F., Cruvinel, D. R., \& Panzeri Pires-de-Souza Fde, C. (2015). Color Stability and Surface Roughness of Composite submitted to Different Types and Periods of Finishing/Polishing: Physical Properties of Composites. J Contemp Dent Pract, 16(7), 565-570. 10.5005/jp-journals-100241723

Dhananjaya KM, Vadavadagi SV, Almalki AS, Verma T, Arora S, Kumar NN (2019) In vitro analysis of different polishing systems on color stability and surface roughness of nanocomposite resins. J Contemp Dent Pract 20(11):1335-1338

Duarte, S., Jr., \& Saad, J. R. (2008). Marginal adaptation of Class 2 adhesive restorations. Quintessence Int, 39(5), 413-419.

Freitas, F., Pinheiro de Melo, T., Delgado, A. H., Monteiro, P., Rua, J., Proença, L.\& Mendes, J. J. (2020). Varying the Polishing Protocol Influences the Color Stability and Surface Roughness of Bulk-Fill Resin-Based Composites. J Funct Biomater, 12(1). 10.3390/jfb12010001 
Research, Society and Development, v. 10, n. 4, e27310414305, 2021

(CC BY 4.0) | ISSN 2525-3409 | DOI: http://dx.doi.org/10.33448/rsd-v10i4.14305

Gönülol, N., \& Yilmaz, F. (2012). The effects of finishing and polishing techniques on surface roughness and color stability of nanocomposites. $J$ Dent, 40 Suppl 2, e64-70. 10.1016/j.jdent.2012.07.005

Hassan, A. M., Nabih, S. M., Mossa, H. M., \& Baroudi, K. (2015). The effect of three polishing systems on surface roughness of flowable, microhybrid, and packable resin composites. J Int Soc Prev Community Dent, 5(3), 242-247. 10.4103/2231-0762.159965

Kaminedi, R. R., Penumatsa, N. V., Priya, T., \& Baroudi, K. (2014). The influence of finishing/polishing time and cooling system on surface roughness and microhardness of two different types of composite resin restorations. J Int Soc Prev Community Dent, 4(Suppl 2), S99-s104. 10.4103/2231-0762.146211

Kocaagaoglu, H., Aslan, T., Gürbulak, A., Albayrak, H., Taşdemir, Z., \& Gumus, H. (2017). Efficacy of polishing kits on the surface roughness and color stability of different composite resins. Niger J Clin Pract, 20(5), 557-565. 10.4103/1119-3077.181387

Lu, H., Roeder, L. B., Lei, L., \& Powers, J. M. (2005). Effect of surface roughness on stain resistance of dental resin composites. J Esthet Restor Dent, 17(2), 102-108; discussion 109. 10.1111/j.1708-8240.2005.tb00094.x

Opdam, N. J., van de Sande, F. H., Bronkhorst, E., Cenci, M. S., Bottenberg, P., Pallesen, U., \& van Dijken, J. W. (2014). Longevity of posterior composite restorations: a systematic review and meta-analysis. J Dent Res, 93(10), 943-949. 10.1177/0022034514544217

Pallesen, U., \& van Dijken, J. W. (2015). A randomized controlled 27 years follow up of three resin composites in Class II restorations. J Dent, 43(12), 15471558. 10.1016/j.jdent.2015.09.003

Schmitt, V. L., Puppin-Rontani, R. M., Naufel, F. S., Nahsan, F. P., Alexandre Coelho Sinhoreti, M., \& Baseggio, W. (2011). Effect of the polishing procedures on color stability and surface roughness of composite resins. ISRN Dent, 2011, 617672. 10.5402/2011/617672

Soliman, H. A. N., Elkholany, N. R., Hamama, H. H., El-Sharkawy, F. M., Mahmoud, S. H., \& Comisi, J. C. (2020). Effect of Different Polishing Systems on the Surface Roughness and Gloss of Novel Nanohybrid Resin Composites. Eur J Dent. 10.1055/s-0040-1718477

Tuncer, D., Karaman, E., \& Firat, E. (2013). Does the temperature of beverages affect the surface roughness, hardness, and color stability of a composite resin? Eur J Dent, 7(2), 165-171.10.4103/1305-7456.110161

Turssi, C. P., Saad, J. R., Duarte, S. L., Jr., \& Rodrigues, A. L., Jr. (2000). Composite surfaces after finishing and polishing techniques. Am J Dent, 13(3), 136138 .

Venturini, D., Cenci, M. S., Demarco, F. F., Camacho, G. B., \& Powers, J. M. (2006) Effect of polishing techniques and time on surface roughness, hardness and microleakage of resin composite restorations. Oper Dent 31 (1): 11-7

Yap, A. U., Yap, S. H., Teo, C. K., \& Ng, J. J. (2004). Finishing/polishing of composite and compomer restoratives: effectiveness of one-step systems. Oper Dent, 29(3), 275-279.

Yazici, A. R., Tuncer, D., Antonson, S., Onen, A., \& Kilinc, E. (2010) Effects of Delayed Finishing/Polishing on Surface Roughness, Hardness and Gloss of Tooth-Coloured Restorative Materials. Eur J Dent.; 4(1): 50-56. 